\title{
Corrosion of pipe steels under alternating currents
}

\author{
Ajit Kumar Thakur ${ }^{1}$, Adarsh Kumar Arya ${ }^{1 *}$, Pushpa Sharma ${ }^{2}$ \\ ${ }^{1}$ Department of Chemical Engineering, UPES, Dehradun, INDIA \\ ${ }^{2}$ Department of Petroleum and Energy Studies, UPES, Dehradun, INDIA \\ *E-mail: akarya@ddn.upes.ac.in
}

Received: 5 August 2021 / Accepted: 30 September 2021 / Published: 10 November 2021

The present paper aims to analyze and compare AC interference on pipeline steel grades in soil simulating solutions. DC current density $\left(\mathrm{J}_{\mathrm{DC}}\right)$ and protection potential $(\mathrm{PP})$ are measured to determine AC interference. The study presents the corrosion resistance of several grades of steel. The paper describes experimental studies involving potentiostatic and galvanostatic measurements. The experimental arrangement has been set up for AC and DC couplings to measure DC current density $\left(\mathrm{J}_{\mathrm{DC}}\right)$, protection potential $(\mathrm{PP})$, and $\mathrm{AC}$ current density $\left(\mathrm{J}_{\mathrm{AC}}\right)$. The paper presents findings on the $\mathrm{AC}$ corrosion behavior of different pipeline steels based on variation in AC current density. The study shows the comparative performance of varying pipe steels. Experimental studies have been conducted on pipe steel in soil simulating solutions under controlled conditions using a specially designed experimental setup. Special care in the experimental setup prevents errors in measurements due to IR drop. The behavior in the field may be influenced by other factors also. The results may be helpful to the pipeline industry in making informed selections of pipe steels subjected to AC interference.

Keywords: Cathodic protection, Pipeline corrosion, X grade pipeline, Protection Potential, Alternating current density

\section{$\underline{\text { FULL TEXT }}$}

(C) 2021 The Authors. Published by ESG (www.electrochemsci.org). This article is an open access article distributed under the terms and conditions of the Creative Commons Attribution license (http://creativecommons.org/licenses/by/4.0/). 